\title{
Effect of texture heterogeneities on the shape memory properties of rolled Fe- Mn-Si SMA
}

\author{
A.V. Druker ${ }^{1}$, C. Sobrero ${ }^{2}$, J. Malarría $^{2}$, U. Garbe $^{3}$, \\ H.-G. Brokmeier ${ }^{3}$, R. E. Bolmaro ${ }^{2, *}$
}

${ }^{1}$ Fac. de Cs. Ex., Ingeniería y Agrimensura, U.N.R. Pellegrini 250, 2000 Rosario, Argentina

2 Inst. de Física Rosario, CONICET-UNR. 27 de febrero 210 bis, 2000 Rosario, Argentina

${ }^{3}$ Institute of Materials Research, GKSS-Research Centre, Max-Planck-Strasse 3, D-21502 Geesthacht, Germany

*bolmaro@ifir-conicet.gov.ar

Keywords: Shape Memory Alloys, Textures, Phase Transformations, Martensitic Transformations

\begin{abstract}
We have investigated an Fe-30Mn-4Si shape memory alloy to clarify the effect, on the bulk texture, of the shear layers resulting from two different thermo-mechanical treatments. XR analysis has shown the existence of texture heterogeneity through the rolled sheet's thickness, due to the effect of friction between sheet and rolls. Neutron diffraction revealed that textured layers on the sheet's surface affect the whole volume. The texture found on the surface of the sheet rolled at $600^{\circ} \mathrm{C}$ is the most favourable for the $\gamma \rightarrow \varepsilon$ martensitic transformation which is the origin of the shape memory effect. Comparing these results with those obtained on sheets rolled at room temperature, we found that shear deformation gradients produce changes in the bulk material texture. Tensile tests initially induce the martensitic transformation in those grains favourably oriented. As a result, these favourable orientations disappear in the remnant austenite.
\end{abstract}

\section{Introduction}

The shape memory effect (SME) is a special thermo-mechanical behaviour which implies the recuperation of apparent plastic deformation; in ferrous alloys, it is due to a stress induced $\gamma$ (austenite, fcc) $\rightarrow \varepsilon$ (martensite, hcp) martensitic transformation, and the inverse transformation obtained by heating to a temperature over the $\mathrm{A}_{\mathrm{f}}[1]$. The shape change should be reversible if the applied deformation does not involve plastic slip and if the martensitic variants creating the forward and reverse transformation are equivalent. Fe-Mn-Si-(Cr-Ni) materials are the ferrous shape memory alloys of higher commercial impact. Due to a low stacking fault energy (SFE), compositions between 28-33\% Mn and 4-6\% Si, maintain the stability of austenite at room temperature and facilitate the formation of stress induced $\mathrm{M}_{\varepsilon}$ without plastic deformation. When the temperature increases, SFE [2,3] also increases, affecting certain properties related to the martensitic transformation. This transformation consists in the 
movement of one Schockley a/6 $\langle 112\rangle$ partial dislocation on alternating $\{111\}$ planes of austenite, changing the stacking sequence by a (111)[112] slip. There are three equivalent slip directions that produce an HCP structure with the same orientation. When the transformation is stress induced, the selective movement of one variant is activated, resulting in the shape change. It means that, among other important factors, the $\gamma \rightarrow \varepsilon$ martensitic transformation is strongly dependent on crystallographic orientation. Research on Fe-Mn-Si single crystals [4], has demonstrated that shape recovery is suppressed if the stress is applied in the $<001>$ direction, but it is almost perfect when the stress occurs in the $<414>$ direction. So, it is expected that a particular preferred orientation or texture, can contribute to good shape recovery properties.

Rolling introduces texture in metallic alloys $[5,6]$. When a metal is obligated to pass through a channel, inevitably the deformation will produce displacement and velocity heterogeneities, which implies gradients in deformation, structure, texture and properties [7]. Some authors $[8,9]$ reported the existence of a correlation between the characteristic parameter $\Delta$ (average relation between thickness and length in the plastic zone) and the surface texture, for different forming processes, temperatures and metals and alloys with different SFE. In addition to roll gap, friction plays a special role in creating shear deformation. These effects are the largest at the roll surfaces, producing, when geometry and/or friction effects are present, a surface texture different than that in the interior. Truszkowski et al $[10,11]$ produced large shear texture gradients in rolled copper and aluminium. Yet, for several low SFE alloys, brass and silver, they could produce only small texture variations through the thickness, for the same rolling condition $[10,12]$. Low SFE promotes twinning as a deformation mode, and as explained by Duggan et al [10], twinning followed by shear banding and slip gives rise to the low-SFE, large-strain rolling texture $\{110\}<112>$ plus $\{110\}<001>$ and a minor $\{111\}<u v w>$ component. In these low SFE materials, a $\{100\}<110>$ shear component twins to $\{122\}<411>$. Following Hutchinson [13], this structure then rotates to $\{100\}<001>$ or $\{111\}<u v w>$. Thus, twinning of the components, formed under heterogeneous conditions followed by slip, produces final textures similar to homogeneous rolling. This situation does not occur in high SFE metals and alloys being the open question whether the results are due to the micromechanics of the deformation or to different contact surface properties and interaction between rolls and samples.

In this work we used X-rays and neutron diffraction to investigate the depth of shear layers in $1 \mathrm{~mm}$ thickness $\mathrm{Fe}-31 \mathrm{Mn}-4 \mathrm{Si}$ sheets rolled at $600^{\circ} \mathrm{C}$ and annealed at $650^{\circ} \mathrm{C}$. Based on the data, we rationalize how those layers affect the bulk texture and analyze how the most favourable textures influence the SME.

\section{Experimental procedures}

The Fe-31Mn-4Si (wt. \%) alloy was melted in an arc furnace, homogenized at $1000^{\circ} \mathrm{C}$ for 24 $\mathrm{h}$ and rolled at $1000^{\circ} \mathrm{C}$ to $1.7 \mathrm{~mm}$. It was then reduced $35 \%$ on several rolling passes at $600^{\circ} \mathrm{C}$ and $20^{\circ} \mathrm{C}$, to a thickness of $1 \mathrm{~mm}$. Finally, the rolled material was annealed at $650^{\circ} \mathrm{C}$ for $20 \mathrm{~min}$. Samples were mechanically and electrolytically polished, using an 80/20 (vol. \%) acetic/ perchloric acid solution. X-ray pole figures were determined using $\mathrm{Cu}-\mathrm{K} \alpha_{1} / \mathrm{K} \alpha_{2}$ lines in a Philips X-pert pro MPD goniometer. Neutron pole figures were measured at Tex-2 goniometer, GKSS, Geesthacht, Germany. Results were analyzed by standard texture and orientation distribution function calculations.

Microstructure was observed by optical microscopy and tensile tests were performed in an 
Instron 1362 testing machine, at a strain rate of $2 \times 10^{-4} \mathrm{~s}^{-1}$. The reverse transformation was obtained by heating at $600{ }^{\circ} \mathrm{C}$ for $15 \mathrm{~min}$, i.e. above the $\mathrm{A}_{\mathrm{f}}$ temperature, in Ar atmosphere to avoid oxidation.

\section{Results and discussion}

\section{Texture measurements}

Figure 1 shows the $\{111\}$ pole figure of austenite, as determined by X-ray and neutron diffraction measurements, on $\mathrm{Fe}-31 \mathrm{Mn}-4 \mathrm{Si}$ sheets rolled under the same $\Delta$ conditions at different temperatures, and annealed at $650^{\circ} \mathrm{C}$ for $20^{\prime}$. Rolling at room temperature, produces a complete stress induced martensitic transformation in the material, with a typical HCP rolling texture. It has transformed back to austenite during annealing, thus maintaining the typical brass rolling components. The neutron diffraction data (figure 1c) indicates a stronger texture than that observed with X-rays (figure 1a). On the other hand, when the sheets are rolled at temperatures over the $\mathrm{A}_{\mathrm{f}}$, the pole figures measured by neutrons show a marked difference with those obtained by using X-rays. The sheet rolled at $600^{\circ} \mathrm{C}$ has a combination of the brass texture components, $\{111\}<112>$, plus a shear texture component $\{100\}<110>$ (near ideal $<441>$ ), on the surface. This alloy experiences an increase in SFE with temperature, and, as it behaves like high-SFE metals, twinning does not occur. Figure 2 is an optical micrograph, which shows a microstructure that is fully twinned. Pole figures measured by neutron diffraction on this sheet (figure 1d), show the contribution of the shear surface components, giving rise to a diminished brass texture, with a weak $\{100\}<110>$ component.

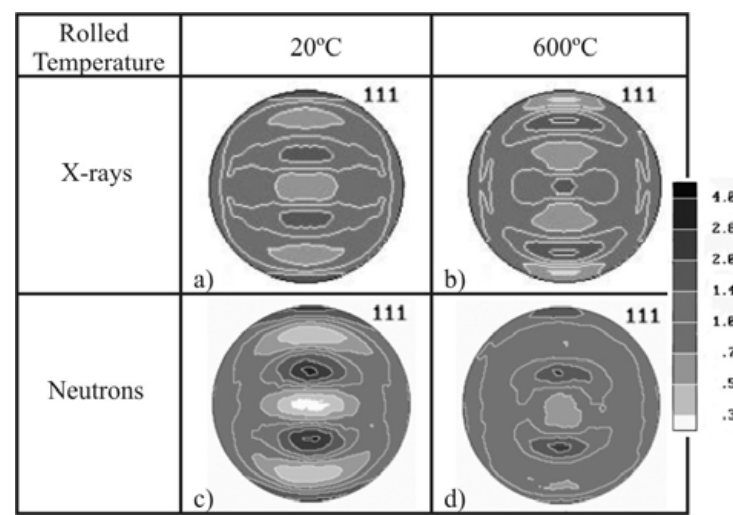

Figure 1. $\{111\}$ pole figures of the sheets rolled at different temperatures after annealing at $650^{\circ} \mathrm{C}$ for $20 \mathrm{~min}$, as measured by $X$-rays and neutron diffraction.

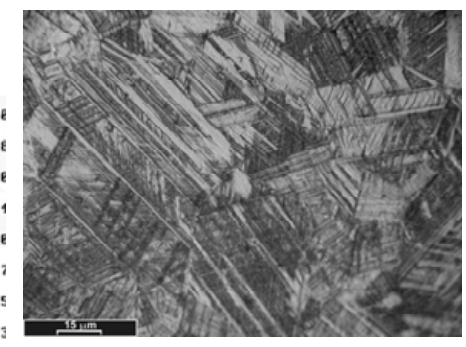

Figure 2. Microstructure of the twinned alloy.

To clarify the effect of deformation heterogeneities in the sheet rolled at $600^{\circ} \mathrm{C}$ and annealed at $650^{\circ} \mathrm{C}$ for $20 \mathrm{~min}$, we performed $\mathrm{X}$-ray analysis at increasing depths bellow the surface in contact with the rolls. This condition, among the studied cases, presented the best shape recovery. For measuring the textures at increasing depth we took advantage of an apparent disadvantage of $\mathrm{Cu} \mathrm{X}$-ray radiation-Fe alloys interaction, that of the high fluorescence and 


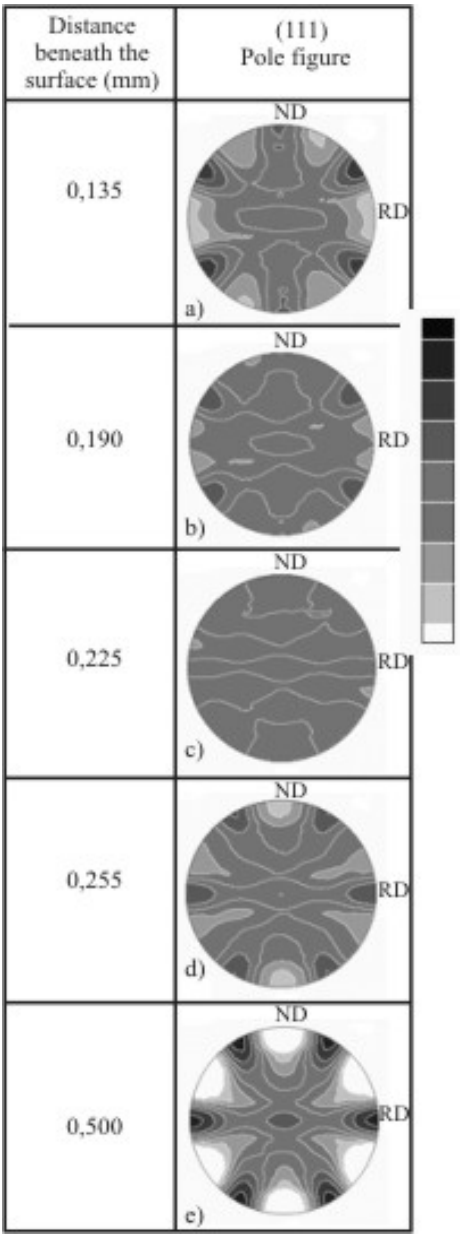

Figure 3. $\{111\}$ pole figures measured at increasing depths beneath the surface of the sheet rolled at $600^{\circ} \mathrm{C}$ and annealed. consequent large absorption effects. By careful mechanical, and further electrolytic polishing by using an 80/20 (vol. \%) acetic/perchloric acid solution, we could take texture data from the very first 5-10 $\mu \mathrm{m}$ after each thinning procedure. Figure 3 summarizes the results, showing $\{111\}$ austenitic pole figures. Figure $3 \mathrm{a}$, taken at 0.135 $\mathrm{mm}$ below the surface, shows a typical FCC shear texture. At $0.19 \mathrm{~mm}$ (figure $3 \mathrm{~b}$ ) and 0.225 $\mathrm{mm}$ (figure $3 \mathrm{c}$ ), we observed a gradual rotation of the shear texture, and at $0.255 \mathrm{~mm}$ (figure $3 \mathrm{~d}$ ) the pole figure is that of a classic rolled FCC brass texture, which is maintained all through to the sheet centre (figure 3e). Inverse pole figures calculated at the sheet surface and centre (figure 4) show a slight textural difference due to deformation heterogeneities. The preferential orientation on the surface is $\{100\}<110>--$ near the $<441>$ orientation--, which activates one of the $\{111\}<112>$ systems responsible of martensitic transformation. On the other hand, there are a majority of grains oriented at $\{110\}<112>$ at the sheet centre. This texture gradient influences the SME because it affects the number of grains favourable oriented for the $\gamma \rightarrow \varepsilon$ martensitic transformation. The contribution of all those components can be integrated creating an average inverse pole figure (figure 5a). Figure 5 also shows the inverse pole figure obtained from neutron diffraction (figure $5 \mathrm{c}$ ) and the same figures corresponding to the sheet rolled at room temperature (figure $5 \mathrm{~b}$ and $5 \mathrm{~d}$, respectively). The figures obtained from the neutron diffraction study, are slightly weaker than those calculated from the weighted average of the different textures measured by X-ray diffraction at different depths. Even averaging different depths' textures the averaging process is not as good as the one performed by neutron diffraction technique.

\section{Texture influence on the shape memory effect}

We have evaluated the SME in the various textured sheets, which were obtained by rolling and annealing at $650^{\circ} \mathrm{C}$. Samples were tensile tested to $3 \%$ permanent deformation, and then heat treated at $600^{\circ} \mathrm{C}$ for $20 \mathrm{~min}$. The thermal treatment reverses the martensitic transformation. Before testing, after testing and after the heat treatment, the lengths were measured 
between two indentation marks made with a Shimadzu micro hardness tester on the sample surface. Results, summarized in Table 1, were calculated as

$$
\mathrm{SME}(\text { in percent })=\frac{l_{1}-l_{2}}{l_{1}-l_{0}} .100
$$

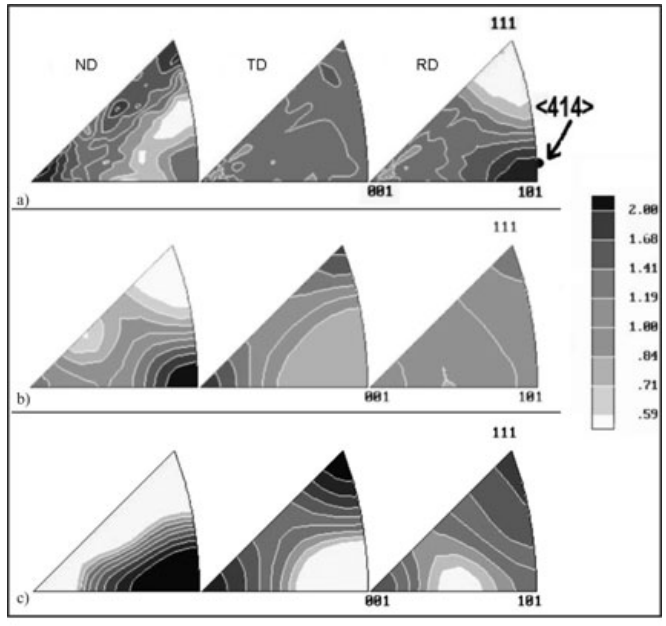

Figure 4. Inverse pole figures of the surface (a) and the centre (b) of the sheet rolled at $600^{\circ} \mathrm{C}$ and annealed, and c) from the specimen surface after tensile deformation.

Figure 5. Inverse pole figures of the austenite corresponding to: a) sheet rolled at $600^{\circ} \mathrm{C}$, b) sheet rolled at room temperature, averaging all X-ray measurements; c) sheet rolled at $600^{\circ} \mathrm{C}$, d) sheet rolled at room temperature, with the inverse pole figures obtained from neutron diffraction data.

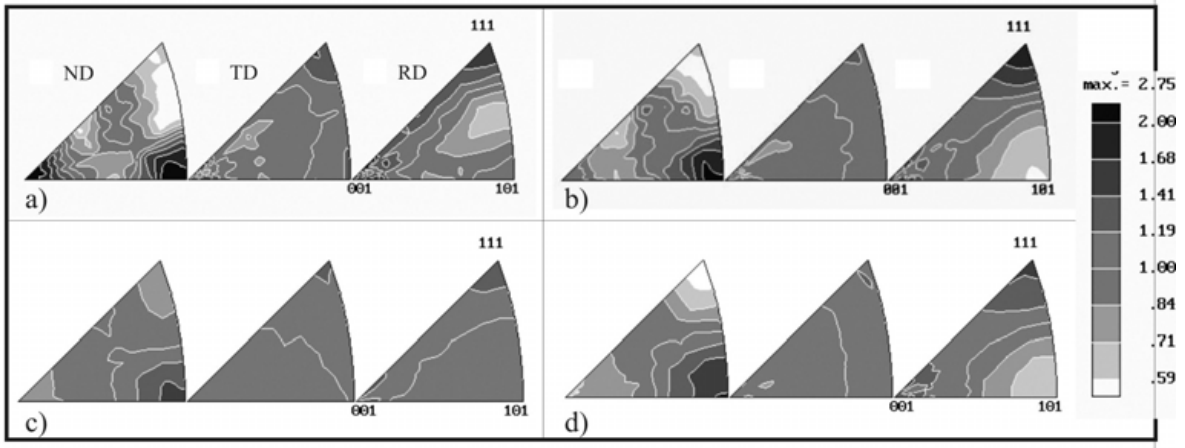

Table 1. SME results, where $\boldsymbol{\sigma}_{\gamma \leftrightarrow \varepsilon}$ is the stress that induces the martensitic transformation and $\boldsymbol{S M E}$ is the percent of deformation recovery.

\begin{tabular}{|c|c|c|}
\hline Sample & $\boldsymbol{\sigma}_{\gamma \leftrightarrow \varepsilon}(\mathrm{MPa})$ & SME (\%) \\
\hline Rolled at $20^{\circ} \mathrm{C}$ and annealed at $650^{\circ} \mathrm{C}$ & 680 & 35 \\
\hline Rolled at $600^{\circ} \mathrm{C}$ and annealed at $650^{\circ} \mathrm{C}$ & 490 & 55 \\
\hline
\end{tabular}


In a previous work [6] we measured the inverse pole figures of the austenite, before and after tensile deformation. The texture component in the rolling direction near the $<441\rangle$ ideal, observed on the surface of the sheets rolled at $600^{\circ} \mathrm{C}$ (figure $4 \mathrm{a}$ ), disappeared when the samples were deformed in tension. The reorientation of the component (figure 4c) would be produced by a martensitic transformation. It should be noted that these sheets have shown the largest SME, compared to those rolled at $20^{\circ} \mathrm{C}$, with the same annealing conditions.

\section{Concluding remarks}

Mechanical processing, like rolling, may produce heterogeneous deformations in materials, through geometrical effects and friction between the sheet and rolls. As a consequence, Xray analyses have shown texture heterogeneities through the thickness of rolled sheets. Neutron diffraction, as well as the calculation of the average of textures measured at different depths beneath the surface, reveals that this textured layer affects the material's bulk behaviour. The surface texture of the alloy processed at $600^{\circ} \mathrm{C}$ is the most favourable for activation of the $\gamma \rightarrow \varepsilon$ martensitic transformation that produces the shape memory effect. Without a favourable surface texture, there is a very little SME in the alloy rolled at room temperature. As texture intensities are low, not above 3 m.r.o., it might be presumptuous to completely attribute differences in SME to this textural variation. However, it is interesting to note that the favourable orientations disappeared from the retained austenite when the $600^{\circ} \mathrm{C}$ rolled material was deformed in tension.

\section{References}

1. Sato, A., Chishima, E., Soma, K. \& Mori, T., 1982, Acta Metall., 30, 1117.

2. Murakami, M., Otsuka, H., Suzuki, H.G. \& Masuda, S., 1986, in Proc. of Int. Conf. on Martensitic Transformation (ICOMAT-86), Japan Inst. Met., p. 985.

3. Allain, S., Chateau, J., Bouaziz, O., Migot, S. \& Guelton, N., 2004, Mat. Sci. Eng. A, 387-389, 158.

4. Sato, A., Chishima, E., Yamaji, Y. \& Mori, T., 1984, Acta Metall., 32, 539.

5. Matsumura, O., Furusako, S., Furukawa, T. \& Otsuka, H., 1996, ISIJ Int., 36, 1103.

6. Druker, A., Sobrero, C., Brokmeier, H.-G., Malarría, J. \& Bolmaro, R., 2006, Mat. Sci. Eng. A, 481-482, 578.

7. Lee, C.S. \& Duggan, B.J., 1991, Metall. Trans., 22A, 11, 2637.

8. Backofen, W.A., 1972, Deformation Processing (Reading, MA: Addison Wesley Publishing Co.), p. 143.

9. Mathur, P.S. \& Backofen, W.A., 1973, Metall. Trans., 4, 643.

10. Truszkowski, W., Krol, J. \& Major, B., 1980, Metall. Trans., 11A, 749.

11. Truszkowski, W., Krol, J. \& Major, B., 1982, Metall. Trans., 13A, 665.

12. Truszkowski, W., Krol, J. \& Major, B., 1982, in Proc. 6th Conf. on Textures of Materials, ISIJ, Tokio, p. 39.

13. Hutchinson, W.B., Duggan, B.J. \& Hatherly, M., 1979, Met. Technol., 32, 1392. 